\title{
The Optimization Research on Nozzle Control Device in Aero Engine Hua-Cong LI ${ }^{1, a}$, Zhe JIANG ${ }^{1, b}$, Jiang-Feng $\mathrm{FU}^{1, \mathrm{c}}, \mathrm{Jia} \mathrm{Li}^{1, \mathrm{~d}}$, Hong-Liang XIAO ${ }^{1, \mathrm{e}}$ \\ ${ }^{1}$ School of Power and Energy, Northwestern Polytechnical University,Xi'an, China

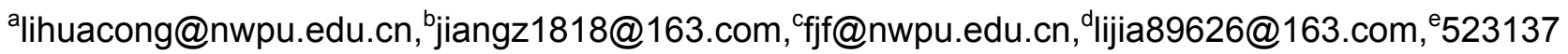 188@qq.com
}

Keywords:aero engine; nozzle control; pressure pulsation; high-precision; optimization

\begin{abstract}
The thesis does the simulation and optimization research aiming at solving the problem of the stability of outlet pulsation in aero engine nozzle control. Based on mathematical model analysis on each component in aero engine nozzle control device, the high-precision modeling of piston pump and controller etc in aero engine nozzle control device was built and studied on simulation and analysis. By comparing the simulated data and experimental data, the error of pressurization value was less than $6 \%$ and working flow was less than $5 \%$, the correctness of the simulation method was verified; On the basis of the results of performance simulation in engine nozzle control device, it analyzed the problems of instability that oil pressure pulsation appears in piston pump included nozzle control device, and simulation and optimization were researched. The optimization results show: modulating the parameters of regulator in controller solves the problem of excessive outlet pressure pulsation in the nozzle control device, then the outlet pressure pulsations is reduced from $6 \mathrm{MPa}$ to $0.5 \mathrm{MPa}$, and the stability of the nozzle control device is improved.
\end{abstract}

\section{Introduction}

Aero engine nozzle control device is used in aero engine nozzle control system, to realize the following function: 1) According to the engine status, a differential pressure is provided of fuel for aero engine nozzle control device and vector nozzle control device; 2) When vent actuator and a thrust vectoring nozzle actuator are on a balance position, nozzle oil pump pressure is maintained [1 2]. Nozzle control device provides a stable high pressure oil source for nozzle control system[3]. Domestic and foreign experts and scholars on the nozzle control device have got some achievements. However, for the special study on stability of aero engine nozzle control device is less. And nozzle control device should provide a stable source of high pressure oil for nozzle control system. But due to the problem of excessive pressure, the nozzle control device outlet pressure pulsation and the instability in the control system are caused, Therefore, to solve the outlet pressure pulsation problems is a key technology break-through for nozzle control device performance[4]. So, study on nozzle control device of high precision modeling and optimization, and solve the stability problem of nozzle control device, which are necessary and meaningful.

Therefore, aiming at stability problem of outlet pressure fluctuation in the aero engine nozzle control device, the thesis analyzes mathematical models all of elements in nozzle control device. Based on high-precision models of piston pumps and controllers and other in the type of nozzle control devices, by comparing of simulation results with experimental data, the correctness of simulation methods is verified. Based on the nozzle control device simulation results, the thesis analyzes instability problems of post-pump oil pressure pulsation in the control device, research for the optimization of the problem.

\section{Working principle of nozzle control device}

Structurally, nozzle control device includes nozzle oil pump, distributing valve, control pistons, fuel solenoid valves, switching valve, implementation valves, and safety valves. Its basic structure is shown in figure 1. 


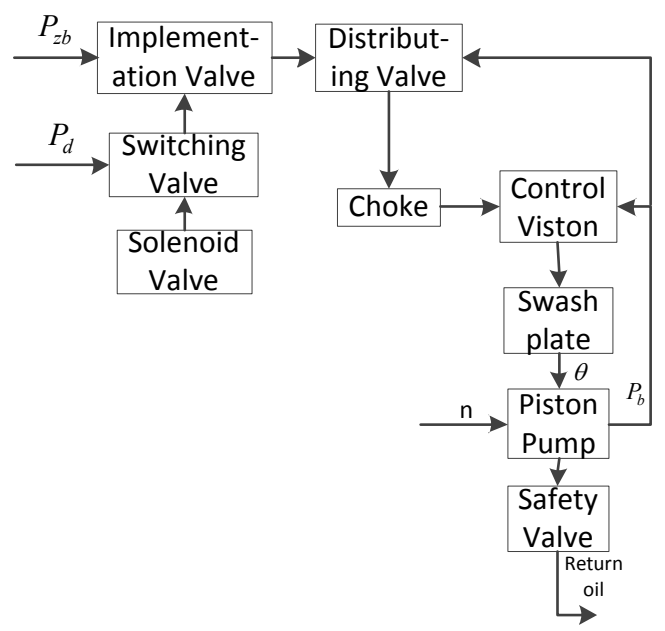

Figure 1 nozzle control system schematic diagram

When the engine is started, main pump pressure can be established. Implementation valve opens return oil circuit, and makes constant pressure oil through switching valve and implementation vales back to the oil circuit, lead valve hydraulic oil is the return oil pressure before distributing, control swash plate angle of piston pumps min. At this point, the nozzle control device is provided low pressure oil, the position of regulation flap is minimum, and the area of vector nozzle is minimum. With the increase of working condition in engine, main pump pressure increases, make the implementation valve gradually shut down, make oil pressure increases in front of the distributing valve, to make piston pumps swash plate angle increases, post-pump pressure increases, At this point, the area of thrust vectoring nozzle is maximum. When needing vector vent actuator action, solenoid valve send out instruction, the return oil circuit of the implementation valve is closed. At this point, the oil pressure in the front of distributing valve increase to , the pressure of post-pump is maximum, and the area of vectoring nozzle is maximum.

\section{MATHEMATICAL MODEL OF NOZZLE CONTROL DEVICE}

The adjustment of the model parameters is based on object models of the underlying mathematical models[5]. Before the modeling and simulations of nozzle control device, first it is needed to analyze mathematical model of nozzle control device. On this basis, building a physical model can set the parameters of the model reasonably and efficiently. So analyze of mathematical model of core components: zero-overlap four-way spool slide valve in the nozzle control device, as is shown in figure 2.

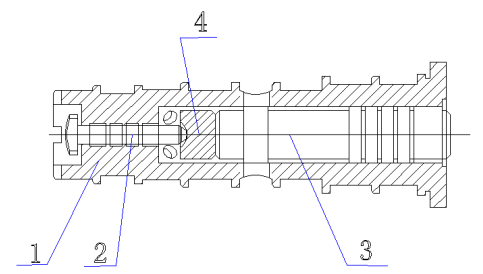

1 bushing; 2 rivet 3 valve core 4 concave

Figure 2 spool valve profile

Equation of zero-overlap four-way spool valve represents characteristic and gain coefficients of spool valve.

$$
\begin{gathered}
q_{v, L}=\mu b y \sqrt{\frac{1}{\rho}\left(p_{n}-p_{L}\right)} \\
K_{q v}=\left(\frac{\partial q_{v, L}}{\partial y}\right) \frac{y_{\max }}{q_{v, L \max }}=\frac{\bar{q}_{v, L, c}}{\bar{y}_{c}}=\sqrt{1-\bar{p}_{v, c}}
\end{gathered}
$$




$$
\begin{aligned}
K_{q p} & =\left(\frac{\partial q_{v, L}}{\partial p_{L}}\right)_{c} \frac{p_{n}}{q_{v, L \max }} \\
& =-\frac{\bar{q}_{v, L, c}}{\bar{y}_{c}}=-\frac{\overline{y_{c}}}{2 \sqrt{1-\bar{p}_{v, c}}} \\
K_{p y} & =-\frac{K_{q y}}{K_{q p}}=\frac{2\left(1-\bar{p}_{v, c}\right)}{y_{c}}
\end{aligned}
$$

Zero-overlap four-way spool slide valve, ${ }^{K_{q y}}$ is the flow gain coefficient, ${ }^{K_{p y}}$ is pressure gain coefficient, which represents gain of the load flow and load pressure on slide-valve displacement $y$, $K_{q y}$ and $K_{p y}$ is larger, and higher sensitivity of slide valve, y small changes will make a big change. $K_{q p}$ is flow-pressure coefficient of slide-valve which is gain of the traffic load on the load pressure. $K_{q y}, K_{p y}$ and $K_{q p}$ with different slide valve operating point change[6].

\section{Modeling and simulation of nozzle control device based on simulation platform}

\section{A. Nozzle control device model}

On the basis of analyzing of structure and principle of nozzle control devices, combining the characteristics of hydraulic components in the library, set up nozzle control device model, as is shown in figure 3 . The single model of nozzle oil pump uses the super element module, as is shown in figure 4.
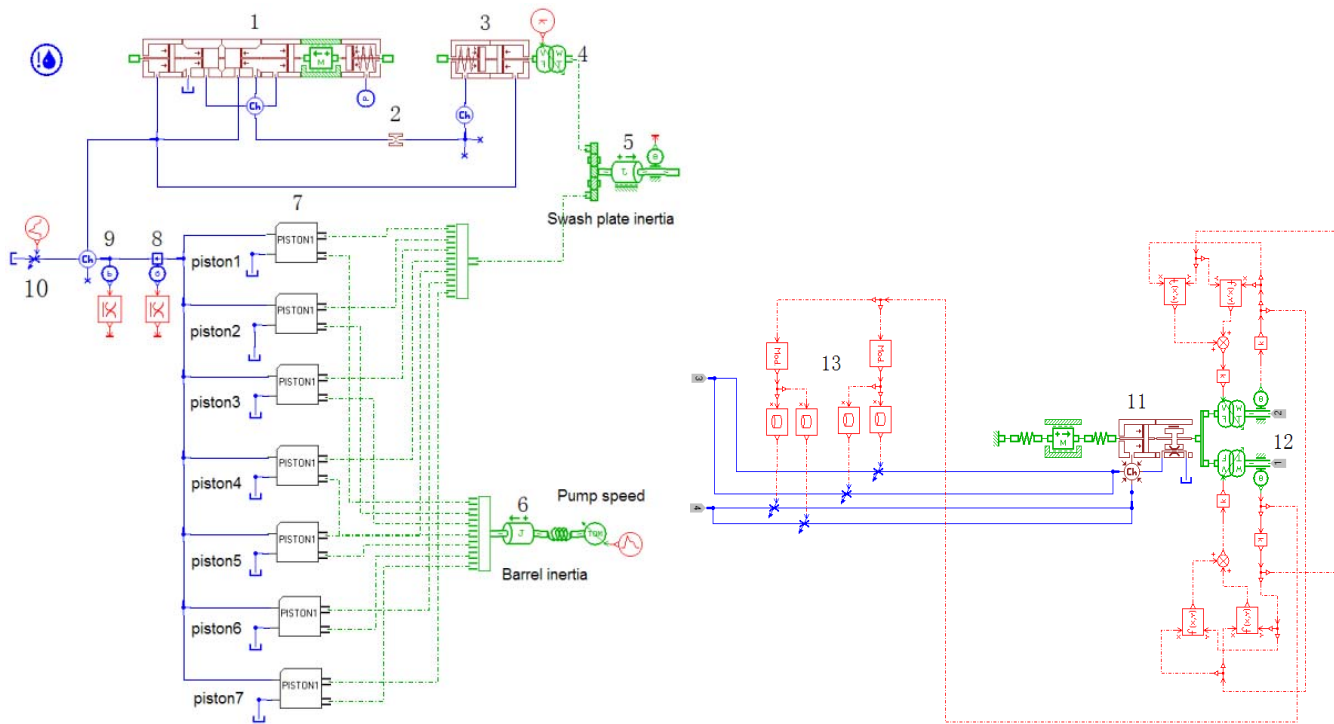

Figure 3 nozzle control device model Figure 4 a single piston models

The simulation results were compared with experimental data to verify the correctness and accuracy of the model. As shown in table 1.

TABLE I. DATA COMPARISON CHART

\begin{tabular}{|c|c|c|c|c|c|}
\hline$P_{k} / \mathrm{MPa}$ & 0.20 & 0.69 & 1.18 & 1.67 & 2.16 \\
\hline$\delta / \%$ & $2 \pm 0.5$ & $2 \pm 0.8$ & $3 \pm 0.4$ & $5 \pm 0.6$ & $5 \pm 0.7$ \\
\hline$\Delta / \%$ & $1 \pm 0.2$ & $1 \pm 0.8$ & $3 \pm 0.5$ & $2 \pm 0.7$ & $4 \pm 0.6$ \\
\hline
\end{tabular}

Note: (1) control oil pressures is $P_{k}$; (2) the error of pressurization value simulation results with experimental data is $\delta$; (3) error of work-flow simulation results with experimental data is $\Delta$.

The data comparison shows: the maximum error of simulation results and experimental data of pressurization value is below $6 \%$, the maximum error of simulation results and test data of workflow is less than $5 \%$, which illustrates modeling and simulation methods are correct.

B. Simulation results of nozzle control device model

Parameter settings: simulation time of $5 \mathrm{~s}$, a sampling interval of $0.001 \mathrm{~ms}$. According to 
conditions set simulation condition: when the speed is $4000 \mathrm{r} / \mathrm{min}$, control pressure $P_{k}$ is $0.20 \mathrm{MPa}$, load diameter $4.9 \mathrm{~mm}$; control pressure $P_{k}$ is $0.69 \mathrm{MPa}$, load diameter $4.48 \mathrm{~mm}$; control pressure $P_{k}$ is $1.18 \mathrm{MPa}$, load diameter $4.21 \mathrm{~mm}$; control pressure $P_{k}$ is $2.16 \mathrm{MPa}$, load diameter $3.82 \mathrm{~mm}$;
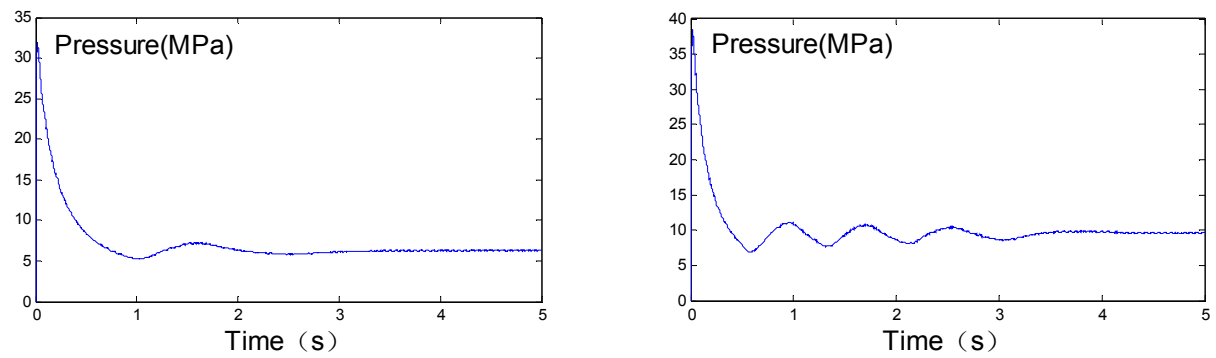

(a) outlet pressure with ${ }^{P_{k}} 0.196 \mathrm{MPA}$
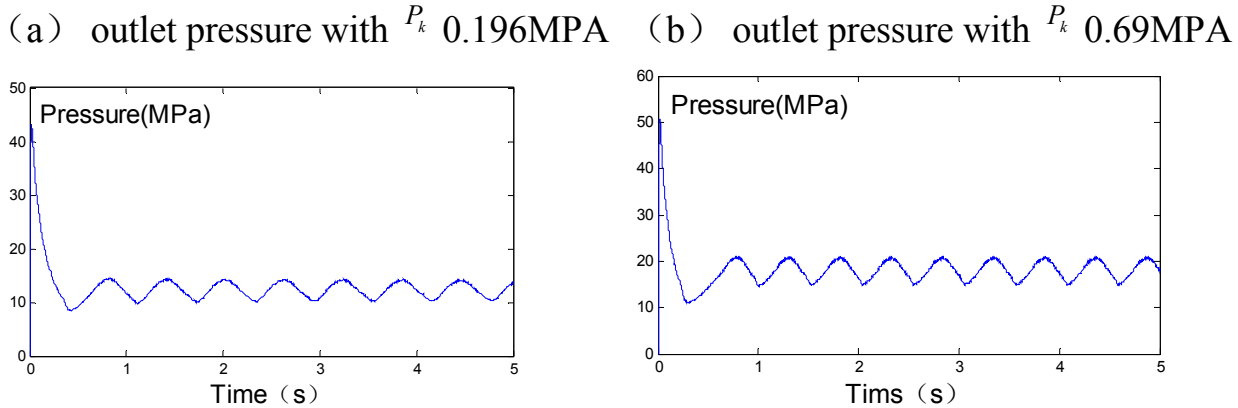

(c) outlet pressure with ${ }^{P_{k}} 1.18 \mathrm{MPA}$ (d) outlet pressure with ${ }^{P_{k}} 2.16 \mathrm{MPA}$

Simulation results: the outlet pressure in the nozzle control device is $10 \mathrm{MPa}$ or less, post-pump pressure is stable, occurs non-pulsating phenomenon; And when the pump pressure is greater than $12 \mathrm{MPa}$, pressure pulsation occurs and pulsating within the scope of $8 \mathrm{MPa}$ range, and the greater the pump pressure, the greater the pressure pulsation, which can not meet the stability performance.

C. Optimization of nozzle control device

Nozzle aero-engine control device needs to offer stable high pressure oil nozzle control system, in accordance with the problem of outlet pressure fluctuation in nozzle control device. It uses optimization scheme by adjusting the control parameter of mediation in controller, to achieve stability performance.

Positive overlap slide valve that lug width is greater than the bushing axial width of window, the stability is good, its circulation area and slide displacement characteristic curve of the valve there is a shadow, also known as a nonlinear relationship[7]. Distributing valve is set to zero and positive overlap, control of oil is $2.16 \mathrm{MPa}$, the post-pump pressure in nozzle control device comparison chart as shown in figure 6.

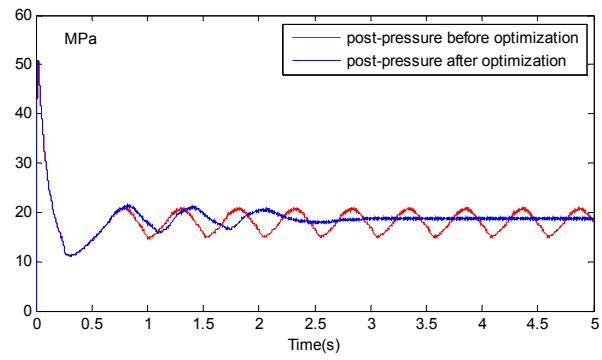

(a) pressure before and after optimization

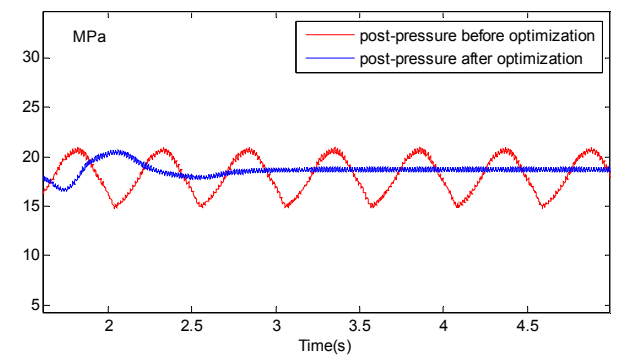

(b) enlarged drawing pressure contrast

Figure (a) can be seen: post- pump pressure appears periodic pulsation phenomenon since $0.5 \mathrm{~s}$, nozzle device cannot be stable before optimization; After optimization, pressure began to stabilize after the $2.2 \mathrm{~s}$, pump pressure pulse disappeared, nozzle control device optimization is achieved.

Figure (b) is an enlarged drawing of the pressure contrast, optimized results show that: when the nozzle control device outlet pressure is $19 \mathrm{MPa}$, the post-pump pressure fluctuation within the scope 
$6 \mathrm{MPa}$, pump pressure is not stable; When using positive overlap in distributing valve, post-pump pressure is $19 \mathrm{MPa}$, the pressure pulse is less than $0.5 \mathrm{MPa}$, and pump outlet pressure is stable.

Simulation results show that by adjusting the modem control parameters in the controller, pump pressure remained stable when up to $19 \mathrm{MPa}$, without large pressure fluctuations, which has realize the optimized purpose of the nozzle control device.

Because a small disturbance exists when the system input, near the steady-state values in the system dynamics, the dead zone may reduce the influence of disturbing signals. In the dynamic process around the steady state of distributing valve, dead zone reduces effects of hydraulic force perturbation signal in the left cavity, which makes nozzle control device stable.

\section{Conclusions}

Conduct the research on problem of outlet pressure pulsation in nozzle control device aero engine, the following results are obtained:

1) Based on mathematical model analysis of the various components in nozzle control device, the thesis sets up high-precision models of pumps, controllers and other in the control devices. Simulation results are compared with experimental data, pressurization values error is less than $6 \%$, flow error is less than 5\%, which shows that the nozzle control device model is high precision, and simulation methods used can be accurately simulated.

2) Nozzle control device simulation results show that piston pump exists the problem of pressure pulse instability in control device.

3) Research on stability optimization of the nozzle control device and results show that adjusting control parameters the conditioner in the controller solves the problem of outlet large pressure fluctuation in nozzle control device, reduces the pumps pressure pulsations from $6 \mathrm{MPa}$ to $0.5 \mathrm{MPa}$, and improves the stability of nozzle control device, achieves optimum results.

\section{References}

[1] FAN Siqi, Li Huacong. Aero engine contol (system portio)[M].Xi'an: North-western Polytechnic University Press, 2008:10-12.(in Chinese)

[2] MAO Kejiu. Aviation propulsion control system [M].Beijing:Beijing Aviation College Press. 1991 :76-89.(in Chinese)

[3] ZENG Junying. Aviation power device control(component portion) [M]. Beijing:Aviation Industry Publishing Company, 1995:118-122.

[4] YANG Gugang, HUANG Meng, FAN Shixin. Aero engine afterburning control typical fault research [J].Aero engine, 2012, 38(3):34-37.(in Chinese)

[5] WANG Qiuxia, FAN Ding, PENG Kai. High speed solenoid valve the application of AMESim[J]. Journal of Aerospace Power, 2014, 29(3): 704-705.

[6] SHAN Fengtong, CHENG Zhenghai. Aviation power plant control laws and Characteristics[M]. Beijing: National Defence Industry Press, 1992:89-94.

[7] FAN Siqi, Li Huacong. Aero engine contol(component portion)[M]. Xi' an: North western Polytechnic University Press,2008:10-12. (in

Chinese) 